Ciência Florestal, Santa Maria, v. 25, n. 3, p. 781-789, jul.-set., 2015

ISSN 0103-9954

\title{
ANÁLISE DE AGRUPAMENTOS EM REMANESCENTE DE FLORESTA ESTACIONAL DECIDUAL
}

\section{CLUSTER ANALYSIS IN SEASONAL DECIDUOUS FOREST REMNANTS}

\author{
Clarice Maboni de Almeida ${ }^{1}$ Maristela Machado Araujo ${ }^{2}$ Solon Jonas Longhi ${ }^{3}$ \\ Ana Paula Rovedder ${ }^{2}$ Marta Silvana Volpato Sccoti ${ }^{4}$ Márcia d'Avila ${ }^{5}$ Suelen Carpenedo Aimi ${ }^{6}$ \\ Thaíse da Silva Tonetto ${ }^{6}$
}

\section{RESUMO}

O objetivo desse estudo foi analisar a presença de agrupamentos na vegetação de um remanescente de Floresta Estacional Decidual, caracterizado como um enclave côncavo, em terreno com declividade acentuada e solo arenoso, entre campos característicos da região. As espécies arbóreas e arbustivas com CAP (circunferência a altura de $1,3 \mathrm{~m}$ do solo) $\geq 15 \mathrm{~cm}$ foram amostradas em duas classes de tamanho. $\mathrm{Na}$ amostragem dos indivíduos da Classe I $(\mathrm{CAP} \geq 30 \mathrm{~cm})$ foram utilizadas 14 parcelas de $20 \mathrm{x} 100 \mathrm{~m}$, divididas em subparcelas $(10 \times 10 \mathrm{~m})$. Os indivíduos da Classe II $(15 \leq \mathrm{CAP}<30 \mathrm{~cm})$ foram observados em 70 subparcelas. Para análise de agrupamentos foi utilizado o programa TWINSPAN, que indicou dois grupos (G1 e G2) bem definidos na Classe I e um grupo relativamente homogêneo na Classe II (sub-bosque). No grupo G1 ocorreram as espécies indicadoras Trichilia claussenii, Cupania vernalis e Crysophyllum marginatum; e no grupo G2 Luehea divaricata e Sebastiania commersoniana. Em relação à estrutura horizontal, essas espécies estiveram entre as três mais importantes nos respectivos grupos. No sub-bosque, as espécies com maior valor de importância foram Actinostemon concolor, Trichilia claussenii, Trichilia elegans, Eugenia rostrifolia e Sorocea bonplandii. Essas espécies, por predominarem na vegetação arbórea, apresentam papel fundamental na estabilização de encostas, considerando que estão adaptadas às áreas com declividade acentuada e solos rasos, destacando-se Cupania vernalis e Trichilia claussenii em ambientes menos alterados e Luehea divaricata e Sebastiania commersoniana em ambientes mais susceptíveis às interferências.

Palavras-chave: fitossociologia; espécies indicadoras; grupo ecológico.

\section{ABSTRACT}

This study intended to analyze the presence of clusters in the vegetation of Seasonal Deciduous Forest

1 Engenheira Floresta, MSc. pelo Programa de Pós-graduação em Engenharia Florestal, Centro de Ciências Rurais, Universidade Federal de Santa Maria, Av. Roraima, 1000, CEP 97105-900, Santa Maria (RS), Brasil. cmaboni@gmail.com

2 Engenheira Florestal, Dr ${ }^{\mathrm{a}}$., Professora do Departamento de Ciências Florestais, Centro de Ciências Rurais, Universidade Federal de Santa Maria, Av. Roraima, 1000, CEP 97105-900, Santa Maria (RS), Brasil. araujo.maristela@gmail.com/anarovedder@gmail.com

3 Engenheiro Florestal, Dr., Professor Titular do Departamento de Ciências Florestais, Centro de Ciências Rurais, Universidade Federal de Santa Maria, Av. Roraima, 1000, CEP 97105-900, Santa Maria (RS), Brasil. longhi.solon@gmail.com

4 Engenheira Florestal, Dr ${ }^{\mathrm{a}}$., Professora Adjunta do Departamento de Engenharia Florestal, Universidade Federal de Rondônia, Campus Rolim de Moura. Av. Norte/Sul, Novo Planalto, CEP 76940-000, Rolim de Moura (RO), Brasil.martasccoti@yahoo.com.br

5 Engenheira Florestal, Dra ., Professora do Centro de Educação Superior Norte, Universidade Federal de Santa Maria, Linha 7 de setembro s/n BR 386, km 40, CEP 98400-000, Frederico Westphalen (RS), Brasil. davilamar@hotmail.com

6 Engenheira Florestal, Doutoranda do Programa de Pós-graduação em Engenharia Florestal, Centro de Ciências Rurais, Universidade Federal de Santa Maria, Av. Roraima, 1000, CEP 97105-900, Santa Maria (RS), Brasil. suaimi@gmail.com / thaisetonetto@hotmail.com

Recebido para publicação em 5/04/2012 e aceito em 9/10/2013

Ci. Fl., v. 25, n. 3, jul.-set., 2015 
remnants, characterized as a concave enclave, on steep sandy soil, among the region's characteristic fields. Shrub and tree specimens with CBH (circumference at breast height) $\geq 15 \mathrm{~cm}$ were sampled in two size classes. In class $\mathrm{I}(\mathrm{CBH} \geq 30 \mathrm{~cm})$ specimen sampling, we used fourteen $20 \mathrm{x} 100 \mathrm{~m}$ plots, divided into sub-plots $(10 \times 10 \mathrm{~m})$. Class II $(15 \leq \mathrm{CBH}<30 \mathrm{~cm})$ specimens were observed in 70 sub-portions. We used the TWINSPAN program to analyze the clusters, which indicated two well-defined clusters in class I (G1 and G2) and one relatively homogenous cluster in class II (understorey). There were Trichilia claussenii, Cupania vernalis and Crysophyllum marginatum indicator species in the G1 cluster; and Luehea divaricata and Sebastiania commersoniana in the G2 cluster. Regarding to horizontal structure, these species were among the three most important ones in both clusters. In the understorey, the most important species were Actinostemon concolor, Trichilia claussenii, Trichilia elegans, Eugenia rostrifolia and Sorocea bonplandii. Since these species prevail in the tree vegetation, they are fundamental to stabilize hillsides, considering that they are adapted to steep and shallow soil areas, pointing out the Cupania vernalis and Trichilia claussenii in less modified environments and the Luehea divaricata and Sebastiania commersoniana in environments more susceptible to interference.

Keywords: phytosociology; indicator species; ecological groups.

\section{INTRODUÇÃO}

A Floresta Estacional Decidual apresenta uma grande diversidade florística, atribuída principalmente às condições climáticas, de solo e regime hídrico. A permanência desses ecossistemas no ambiente depende do controle de fatores causadores da degradação, pois a fragmentação florestal produz alterações com perdas genéticas, dificultando a manutenção das espécies.

A conservação dos ecossistemas requer alguns cuidados, no sentido de minimizar interferências que possam vir a alterar a estrutura e composição das espécies. Entretanto, depende do conhecimento sobre as populações envolvidas e, consequentemente, da comunidade como um todo. Estudos sobre esses ambientes permitem entender o grau de conservação da floresta, como indicador da sua qualidade e necessidade de medidas a serem tomadas, de modo a traçar estratégias e ações de restabelecimento (RIO GRANDE DO SUL, 2007).

As florestas são formadas por meio de sucessão, tendo em vista que espécies adaptadas às condições de maior luminosidade colonizam áreas abertas, crescendo rapidamente e fornecendo sombreamento para o estabelecimento de espécies mais tardias. A separação das espécies arbóreas em grupos ecológicos, conforme suas exigências e funções, facilita seu entendimento e manejo. Por esse motivo, são informações importantes nos projetos de recuperação de ambientes alterados.

Muitos trabalhos foram realizados buscando melhorar o aprendizado no que se refere à fitossociologia, pois a vegetação natural é complexa e está relacionada a diversos fatores do meio, como: climáticos, pedológicos e biológicos. Para analisá-la, podem ser utilizados parâmetros, entre os quais se destacam os métodos florísticos ou taxonômicos e os baseados na estrutura.

$\mathrm{O}$ estudo da composição florística, associado à ocorrência e desenvolvimento de cada indivíduo, conduz ao conhecimento da estrutura da vegetação, possibilitando informações qualitativas e quantitativas sobre a floresta, o que facilita a tomada de decisões e o manejo de florestas. A fitossociologia é extremamente importante, pois estuda as comunidades vegetais no que se refere a sua origem, estrutura, classificação, relacionando aos fatores do meio (FELFILI e RESENDE, 2003). Neste sentido, Hill et al. (1975) desenvolveram um método denominado "Análise de espécies indicadoras" como forma de conciliar variáveis qualitativas (espécies) e quantitativas (densidade), utilizando, para isso, as pseudoespécies. Baseado nesse método, Hill (1979) desenvolveu o programa TWINSPAN (TWo-way INdicator SPecies ANalysis), como forma de suprir necessidades de ecologistas e fisiologistas. O TWINSPAN é um procedimento multivariado que classifica as unidades em grupos relativamente homogêneos. O resultado final são divisões das unidades amostrais, com seus respectivos autovalores, espécies indicadoras e preferenciais de cada agrupamento. Cada divisão obtém um autovalor, que representa quanto da variação dos dados na comunidade foi explicada no eixo de ordenação (McCUNE 
e MEFFORD, 2006). Autovalor igual ou maior de 0,30 é suficiente para explicar as variações em dados obtidos na natureza (FELFILI et al., 2007), apresentando forte relevância na determinação da variação dos dados.

$\mathrm{Na}$ caracterização da estrutura horizontal da vegetação são utilizados parâmetros como: densidade, dominância, frequência e valor de importância para as espécies presentes, além de índices de diversidade, como o de Shannon (H') e a equabilidade $(\mathrm{J})$, que representam a comunidade, e são amplamente utilizados em estudos da vegetação (RIBEIRO et al., 2007; MORO e MARTINS, 2011; SCIPIONI et al., 2011).

Assim, o presente estudo teve como objetivo caracterizar a vegetação arbórea de um remanescente de Floresta Estacional Decidual em Santa Maria RS, por meio dos seguintes questionamentos: a) na vegetação, ocorrem agrupamentos? b) quais são as espécies indicadoras da vegetação? c) quais são os possíveis fatores que influenciam a vegetação? d) quais são as espécies fundamentais na estabilização da área?

\section{MATERIAL E MÉTODOS}

O trabalho foi desenvolvido em remanescente de Floresta Estacional Decidual (53.52'O e 29.46'S), localizado no Campo de Instrução de Santa Maria (CISM), município de Santa Maria - RS. O remanescente estudado apresenta aproximadamente 560 hectares. O relevo no local varia de levemente ondulado a declividades acentuadas (FARIAS et al., 1994). A área do remanescente florestal caracteriza-se por um enclave de elevada profundidade e declividade em meio às coxilhas suave-onduladas, típicas da topossequência da Depressão Central. Essa área representa a tipologia de remanescentes, comumente observados na região Sul.

No local, conforme Almeida (2010), o solo das encostas mais declivosas foi classificado como Neossolo Litólico, caracterizado por pedogênese recente, pouco profundo, com horizonte A assentado sobre saprolito ou diretamente sobre a rocha matriz. No fundo do vale escarpado, foi encontrado Neossolo Quartzarênico, também caracterizado por pedogênese recente, mas com elevada profundidade e horizonte $A$ assentado sobre horizonte $C$ não consolidado. Em ambos os solos, o material de origem é constituído de rochas sedimentares, sendo arenito o material mais frequente, em associação com argilitos e siltitos. A constituição original do solo proporciona alta friabilidade; baixa capacidade reativa, devido ao reduzido complexo de cargas positivas e negativas; porosidade do tipo textural, evidenciada pela reduzida ou ausente agregação do material e elevado teor de areia, assim, predominando a macroporosidade. Essas características conferem à área uma reduzida capacidade de retenção de moléculas e íons, além de baixa retenção de água e elevada capacidade de infiltração.

No passado, a área de estudo fez parte da Fazenda Sarandi, onde foi extraída madeira de espécies de interesse na propriedade e para fins econômicos. $\mathrm{Na}$ ocasião do inventário florestal realizado para obtenção dos dados apresentados nesse estudo, o campo adjacente à floresta estava sendo utilizado para pastoreio do gado que ocupava a mata como abrigo.

A vegetação foi avaliada em 14 parcelas de $20 \times 100 \mathrm{~m}$, divididas em subparcelas de $10 \mathrm{x}$ $10 \mathrm{~m}$, distribuídas sistematicamente na floresta. $\mathrm{Na}$ sistematização foram locadas quatro faixas distantes $500 \mathrm{~m}$ entre si, dentro das quais foram marcadas parcelas em intervalos de $200 \mathrm{~m}$. Para a avaliação da Classe I (estrato superior), representada por indivíduos com circunferência a $1,3 \mathrm{~m}$ da superfície do solo $(\mathrm{CAP} \geq 30 \mathrm{~cm}$ ), foram utilizadas 280 subparcelas. Na avaliação dos indivíduos da Classe II $(15 \mathrm{~cm} \leq \mathrm{CAP}<30 \mathrm{~cm})$ foram sorteadas cinco subparcelas por parcela, totalizando 70 subparcelas para estudo da vegetação do sub-bosque. Os indivíduos foram identificados e medidos (CAP) com o auxílio de fita centimétrica.

Aidentificação das espécies foi feita no local, coletando-se material botânico de cada espécie, o qual foi encaminhado ao Herbário do Departamento de Ciências Florestais da Universidade Federal de Santa Maria (HDCF), para confirmação e/ou identificação.

Considerou-se que a amostragem foi satisfatória, pois foi observado que ao aumentar $10 \%$ da área, menos de $10 \%$ de novas espécies foram identificadas, conforme descrito por MuellerDombois e Ellemberg (1974), método também utilizado em estudo fitossociológico por Scipioni et al. (2009). Desse modo, a amostragem foi maior do que a necessária para representar a vegetação arbórea e arbustiva, considerando que 1,30 e 0,54 ha foram suficientes para representar, respectivamente, as Classes I e II.

$\mathrm{Na}$ análise de agrupamento para ambas 
as classes, utilizou-se o programa TWINSPAN (TWo-way INdicator SPecies ANalysis), que, por análise multivariada, agrupa unidades (subparcelas) e espécies semelhantes, por meio dos seguintes pontos de corte: $0,2,5,10$ e 20 , os quais indicam o intervalo para cada pseudoespécie. Para a Classe I, utilizou-se uma matriz de $273 \times 47$, pois sete subparcelas não apresentaram indivíduos com CAP $\geq 30 \mathrm{~cm}$, e para a Classe II, de $70 \times 41$. Nas duas matrizes, 273 e 70 linhas representaram as subparcelas, e 47 e 41 colunas, as espécies, para Classes I e II, respectivamente.

A caracterização da estrutura horizontal da vegetação utilizou os seguintes parâmetros na forma relativa: densidade (DR), frequência (FR), dominância (DoR) e valor de importância (VI\%). A diversidade de espécies em nível de comunidade foi obtida pelo Índice de Diversidade de Shannon (H') e a Índice de equabilidade de Pielou (J), conforme Brower e Zar (1984) Felfili e Resende (2003). Os índices H'e J foram calculados para as Classes I e II e para os grupos formados.

As espécies presentes em ambas as classes foram classificadas de acordo com o grupo ecológico em: inicial (pioneira e/ou secundária inicial), tardia (secundária tardia e/ou clímax), plástica (às vezes descrita como espécie inicial e outras como tardia, tolerante à sombra), e não identificada.

\section{RESULTADOS E DISCUSSÃO}

No remanescente florestal foram observadas 62 espécies. Na Classe I, a riqueza florística de 55 espécies foi expressa pelo Índice de Diversidade de Shannon igual a 3,41 e pelo Índice de Equabilidade de Pielou, que resultou em 0,84, reduzindo na Classe II para 37, 1,66 e 0,46, respectivamente. Ambas as classes apresentaram similaridade de proporção de espécies iniciais e tardias (Figura 1), o que sugere uma expressiva dinâmica sucessional na floresta, provavelmente, devido à fragilidade do ambiente, dada a declividade acentuada no local, que aumenta a frequência de queda de árvores e aberturas de clareiras, para o desenvolvimento de espécies de estágio inicial.

Conforme Denslow (1987), a dinâmica de clareiras imposta pela queda natural de árvores proporciona que espécies de grupos ecológicos diferentes ocorram conjuntamente. Nesse sentido, a presença de solos rasos na área, associada à declividade, pode ser fator determinante para

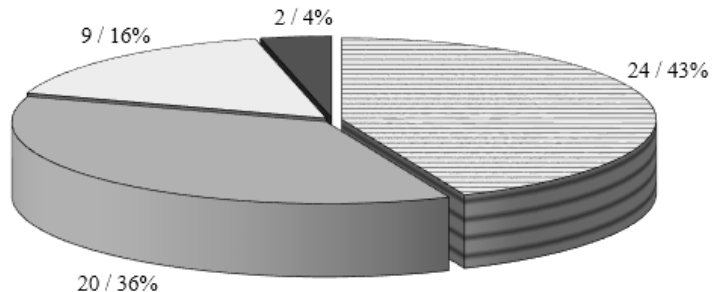

(A)

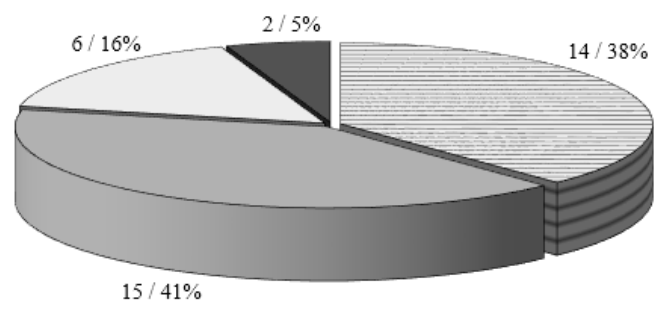

$\boxminus$ Inicial $\square$ Tardia $\square$ Plástica $\square$ Não identificada

FIGURA 1: Classificação das espécies por grupo ecológico (número de espécies/ percentual), considerando os indivíduos da Classe I $(\mathrm{CAP} \geq 30 \mathrm{~cm})$ (A) e Classe II $(15 \mathrm{~cm} \leq \mathrm{CAP}<30$ $\mathrm{cm})(\mathrm{B})$, em remanescente de Floresta Estacional Decidual, Santa Maria RS.

FIGURE 1: Species classification by ecological cluster (number of species / percentage), considering Class I $(\mathrm{CBH} \geq 30 \mathrm{~cm})(\mathrm{A})$ and Class II $(15$ $\mathrm{cm} \leq \mathrm{CBH}<30 \mathrm{~cm}$ ) (B) species, in Seasonal Deciduous Forest remnants, Santa Maria, RS state.

a característica do remanescente em estágio sucessional intermediário, considerando que nessa circunstância ocorrem formações de clareira pela queda de árvores, proporcionando que novos indivíduos se estabeleçam.

\section{Análise de agrupamentos}

A classificação das amostras da Classe I (estrato superior) identificou duas situações distintas na vegetação, assim, definindo os grupos G1 e G2, com autovalor de 0,38 (Figura 2). Na Classe II (sub-bosque) apenas 3 parcelas foram classificadas como diferentes das outras 67 , apesar do expressivo autovalor $(0,40)$.

No estrato superior, o G1 está localizado em parcelas com menor alteração e apresenta como espécies indicadoras: Trichilia claussenii DC, Cupania vernalis Cambess e Crysophyllum 


\begin{tabular}{|c|c|c|}
\hline \multicolumn{3}{|c|}{ Conjunto de subparcelas } \\
\hline Grupo 1 & Autovalor: 0,3808 & Grupo 2 \\
\hline 139 subparcelas & \multicolumn{2}{|c|}{134 subparcelas } \\
\hline $\begin{array}{l}\text { Espécies Indicadoras: Trichilia claussenii 1, } \\
\text { Cupania vernalis 1 e Crysophyllum marginatum } 1\end{array}$ & $\begin{array}{l}\text { Espécies Indicadoras } \\
\text { Sebastiania commersonia }\end{array}$ & lea divaricata $1 \mathrm{e}$ \\
\hline $\begin{array}{l}\text { Espécies Preferenciais: Crysophyllum marginatum } \\
1(48,9) \text {, Cupania vernalis } 1(63,18), \text { Trichilia } \\
\text { catigua } 1(29,2) \text {, Trichilia claussenii } 1(76,17) \mathrm{e} \\
\text { Trichilia claussenii } 2(38,2)\end{array}$ & $\begin{array}{l}\text { Espécies Preferencia } \\
(2,26), \text { Cordia americ } \\
\text { divaricata } 1(7,40), \mathrm{e} S \\
1(1,34)\end{array}$ & $\begin{array}{l}\text { earia sylvestris } 1 \\
3,21), \text { Luehea } \\
\text { ania commersoniana }\end{array}$ \\
\hline
\end{tabular}

FIGURA 2: Classificação das unidades amostrais em dois grupos, caracterizando as formações em remanescente de Floresta Estacional Decidual, Santa Maria - RS.

FIGURE 2: Sample unit classification in two clusters, characterizing the formation of Seasonal Deciduous Forest remnants, Santa Maria, RS state.

marginatum (Hook \& Arn.) Radlk., com a pseudoespécie 1 que caracteriza a ocorrência de um indivíduo por subparcela. A presença dessas espécies no ambiente indica um processo de sucessão intermediário que, segundo Odum (1997), nos ecossistemas naturais precede a "estabilidade".

Em trabalho elaborado pela Secretaria Estadual do Meio Ambiente (SEMA) estas espécies foram classificadas como secundárias tardias, por se estabelecerem em locais de menor intensidade luminosa, indicando a existência prévia de espécies de estágios iniciais (RIO GRANDE DO SUL, 2007).

Por outro lado, em cada fase sucessional, além de ocorrer espécies que demandam determinada intensidade luminosa, representando os grupos ecológicos ou sucessionais, a presença das espécies pode ser influenciada pela topografia, tipo de solo ou outros fatores abióticos. Na área de estudo, a irregularidade do terreno, associada a solos rasos, determina a ocorrência de espécies com sistema radicular bem desenvolvido, aptas a se estabelecer $\mathrm{e}$, consequentemente, dar estabilidade à área.

Além das espécies indicadoras, a Trichilia catiguá A. Juss., com a pseudoespécie 1, e a Trichilia classenii (pseudoespécie 2), com 2 a 4 indivíduos por unidade amostral, representaram as espécies preferenciais desse grupo que, juntamente com as indicadoras, foram as principais responsáveis pela classificação do G1.

O grupo G2 foi formado pelas subparcelas com maior alteração. As espécies indicadoras neste grupo foram Luehea divaricata Mart. e Sebastiania commersoniana (Bail.) L. B. Sm. \& Downs, ambas representadas pela pseudoespécie 1. A presença dessas espécies ao ambiente, provavelmente, devese a sua maior rusticidade, pois, de acordo com Lorenzi (2002a,b), são plantas heliófilas, seletivas higrófitas, frequentemente encontradas em terrenos íngremes, nos quais a floresta é mais aberta. Tais características das espécies indicadoras confirmam a situação de maior intervenção no $\mathrm{G} 2$, devido à instabilidade do terreno, proporcionada pela declividade acentuada, a presença de Neossolo originado de rochas sedimentares e acesso do gado, fatores esses determinantes na dinâmica da paisagem e, consequentemente, no destaque às espécies iniciais.

Além das espécies indicadoras, as preferenciais do grupo G2 foram Casearia sylvestris Sw. do grupo das secundárias iniciais, e Cordia americana (L.) Gottschling \& J. E. Mill., de comportamento plástico, descrita como inicial ou tardia.

Na Classe II (sub-bosque), em razão de somente três subparcelas terem sido classificadas como um grupo, independentemente das demais, optou-se por analisá-la como estrato homogêneo, sem a formação de agrupamentos. Cabendo esclarecer que essa divisão aconteceu em virtude da Cordia americana e da Casearia sylvestris terem ocorrido em maior densidade nas três subparcelas, fato que é considerado relevante pelo método de classificação utilizado nesse estudo, entretanto, aqui desconsiderado, devido a essas mesmas espécies terem ocorrido também no grupo 
oposto.

\section{Composição florística e estrutura dos agrupamentos}

A partir dos agrupamentos formados na vegetação da Classe I $(C A P \geq 30 \mathrm{~cm})$ na composição florística do remanescente estudado, foram observadas, em G1, 52 espécies arbóreas pertencentes a 43 gêneros e 24 famílias. As famílias Myrtaceae e Sapindaceae destacaram-se das demais em relação ao número de espécies (7 e 6 , respectivamente).

$\mathrm{O}$ índice de Shannon (H') gerou um valor de 3,12, indicando uma diversidade que pode ser considerada intermediária, assim como a equabilidade (J) de 0,79 , que representa a proporção de distribuição de indivíduos entre as espécies, ou seja, quando o valor é próximo de "um" significa que as espécies apresentam número semelhante de indivíduos. Na região, Longhi et al. (1999) identificaram, em estudo realizado em fragmento florestal, a diversidade de 3,21 , enquanto Scipioni et al. (2009), verificaram diversidade de 3,35 e equabilidade de 0,81 . Assim, observa-se que os valores descritos pelos autores, são próximos àqueles obtidos para $\mathrm{G} 1$, apesar dos poucos indícios de alteração antrópica nesse grupo.

As espécies com maior valor de importância (VI) no G1 foram Cupania vernalis (14,29\%), Trichilia claussenii (13,05\%), Chrysophyllum marginatum (7,31\%), Nectandra megapotamica (Spreng.) Mez (5,12\%) e Plinia rivularis (Cambess.) Rotman (4,92\%).

$\mathrm{Na}$ hierarquização dessas espécies, observou-se que Cupania vernalis e Trichilia claussenii representaram, aproximadamente, 31\% da densidade de indivíduos arbóreo-arbustivos com $\mathrm{CAP} \geq 30 \mathrm{~cm}$ e $27 \%$ da dominância, correspondente à área basal (Tabela 1). Entretanto, ressalta-se que Cupania vernalis apresentou indivíduos com maiores diâmetros, atingindo o estrato superior na área de estudo, enquanto a Trichilia claussenii, apesar de abundante, desenvolveu menor área basal, ocupando geralmente, estrato inferior a médio. Assim, destacam-se essas espécies como potenciais para se estabelecer em áreas declivosas e com solos rasos, desde que apresentem reduzida interferência.

Em menor escala, mas ainda entre as mais representativas no G1, Crysophyllum marginatum teve todos os parâmetros (densidade, frequência e dominância), contribuindo para seu posicionamento hierárquico na vegetação. Já Nectandra megapotamica se destacou pela dominância, enquanto Plinia rivularis, pela densidade e frequência (Tabela 1).

O grupo G2 apresentou 53 espécies, 44 gêneros e 24 famílias. A família Myrtaceae foi mais bem representada com sete espécies, seguida por Sapindaceae com seis espécies. O índice de Shannon para este grupo foi de 3,39, superior ao G1, o que ocorreu, principalmente, devido à maior equabilidade $(0,85)$, sendo esses valores próximos ao observado por Scipioni et al. (2009), na mesma região de estudo.

As espécies mais bem hierarquizadas, por meio do valor de importância (VI), foram Luehea divaricata (10,84\%), Cordia americana (7,69\%), Sebastiania commersoniana (6,55\%), Nectandra megapotamica (6,10\%) e Myrcianthes pungens (O.Berg) D. Legrand (6,09\%) (Tabela 1).

Nesse grupo, destacaram-se as três primeiras com, aproximadamente, $22 \%$ da densidade de indivíduos arbóreos. Observa-se, na Tabela 1, que Luehea divaricata e Cordia americana ficaram fortemente representadas por árvores de maior diâmetro, dando suporte para seus indivíduos de maior altura, que ocupam o dossel da floresta, enquanto Sebastiania commersoniana predominou no estrato médio.

Ressalta-se em G2 maior alteração de estrutura do que em G1, induzindo uma dinâmica expressiva na vegetação, evidenciada pelas espécies mais bem hierarquizadas (Luehea divaricata, Cordia americana e Sebastiania commersoniana), caracterizadas por serem heliófilas e comumente encontradas nas encostas de morros na região.

Conforme Araujo et al. (2004), essas espécies são comumente observadas nas florestas ciliares, estabilizando as margens ou locais com forte ação do extravasamento do rio pelas enchentes, o que sugere a presença de sistema radicular bem desenvolvido, apto para dar suporte à árvore e, consequentemente ao terreno, semelhante à função realizada na área de estudo.

Myrcianthes pungens teve todos os parâmetros (DR, FR, DoR), contribuindo para sua efetiva representatividade no agrupamento, a qual, sendo uma secundária tardia e pouco requerida para o uso madeireiro, possivelmente, foi mantida na área, cabendo observação da sua potencialidade nessas áreas menos estabilizadas. Da mesma forma que em G1, a Nectandra megapotamica teve 
TABELA 1: Parâmetros fitossociológicos e grupo ecológico da vegetação em remanescente de Floresta Estacional Decidual, Santa Maria - RS. Classe I (CAP $\geq 30 \mathrm{~cm})$ : Grupos 1 e 2; Classe II $(15 \leq$ CAP $<30 \mathrm{~cm}$ ): sub-bosque.

TABLE 1: Phyto-sociologic parameters and vegetation ecological cluster in Seasonal Deciduous Forest remnants, Santa Maria, RS state. Class I $(\mathrm{CBH} \geq 30 \mathrm{~cm})$ : Clusters 1 and 2; Class II ( $15 \leq \mathrm{CBH}$ $<30 \mathrm{~cm}$ ): sub-forest.

\begin{tabular}{|c|c|c|c|c|c|c|c|c|c|c|c|c|c|}
\hline \multirow{3}{*}{ Fam/GE } & \multirow{3}{*}{ Espécie } & \multicolumn{8}{|c|}{ Classe I } & \multirow{2}{*}{\multicolumn{4}{|c|}{$\begin{array}{c}\text { Classe II } \\
\text { Grupo } 1 \text { e } 2\end{array}$}} \\
\hline & & \multicolumn{4}{|c|}{ Grupo 1} & \multicolumn{4}{|c|}{ Grupo 2} & & & & \\
\hline & & DR & FR & DoR & $\begin{array}{l}\text { VI } \\
\%\end{array}$ & DR & FR & DoR & $\begin{array}{l}\text { VI } \\
\%\end{array}$ & DR & FR & DoR & $\begin{array}{l}\text { VI } \\
\%\end{array}$ \\
\hline $\mathrm{Eu} / \mathrm{P}$ & Actinostemon concolor (Spreng.) Müll. Arg. & & & & & & & & & 57,3 & 21,5 & 53 & 43,9 \\
\hline $\mathrm{La} / \mathrm{T}$ & Aiouea saligna Meisn & & & & & & & & & 1,84 & 3,75 & 2,32 & 2,64 \\
\hline $\mathrm{Sal} / \mathrm{P}$ & Banara tomentosa $\mathrm{Clos}$ & 3,11 & 3,75 & 1,32 & 2,73 & & & & & & & & \\
\hline $\mathrm{My} / \mathrm{T}$ & Campomanesia xanthocarpa $\mathrm{O}$. Berg & 2,46 & 2,9 & 1,82 & 2,39 & & & & & & & & \\
\hline $\mathrm{Sal} / \mathrm{I}$ & Casearia sylvestris $\mathrm{Sw}$. & & & & & 6,19 & 5,18 & 2,52 & 4,63 & 1,47 & 3,75 & 1,9 & 2,37 \\
\hline $\mathrm{Sap} / \mathrm{T}$ & $\begin{array}{l}\text { Chrysophyllum marginatum (Hook. \& Arn.) } \\
\text { Radlk. }\end{array}$ & 7,26 & 8,19 & 6,49 & 7,31 & & & & & & & & \\
\hline $\mathrm{Bo} / \mathrm{P}$ & $\begin{array}{l}\text { Cordia americana (L.) Gottschling \& J. E. } \\
\text { Mill. }\end{array}$ & & & & & 6,19 & 5,36 & 11,5 & 7,69 & & & & \\
\hline $\mathrm{Sa} / \mathrm{T}$ & Cupania vernalis Cambess. & 14,5 & 10,9 & 17,4 & 14,3 & 5,01 & 3,33 & 4,47 & 4,27 & & & & \\
\hline $\mathrm{My} / \mathrm{T}$ & Eugenia rostrifolia D.Legrand & 3,63 & 4,1 & 1,13 & 2,95 & 3,69 & 4,07 & 1,5 & 3,08 & 2,58 & 4,44 & 2,89 & 3,3 \\
\hline $\mathrm{Ma} / \mathrm{I}$ & Luehea divaricata Mart. & & & & & 6,93 & 7,39 & 18,2 & 10,8 & & & & \\
\hline $\mathrm{My} / \mathrm{T}$ & Myrcianthes pungens (O.Berg) D. Legrand & 3,5 & 4,44 & 5,29 & 4,41 & 6,19 & 6,1 & 5,98 & 6,09 & 1,47 & 3,75 & 1,47 & 2,23 \\
\hline $\mathrm{La} / \mathrm{T}$ & Nectandra megapotamica (Spreng.) Mez & 3,63 & 4,44 & 7,3 & 5,12 & 4,42 & 4,25 & 9,62 & 6,1 & & & & \\
\hline $\mathrm{Fa} / \mathrm{I}$ & Parapiptadenia rigida (Benth.) Brenan & & & & & 3,24 & 3,7 & 4,7 & 3,88 & & & & \\
\hline My/I & Plinia rivularis (Cambess.) Rotman & 5,71 & 5,29 & 3,77 & 4,92 & 6,19 & 5,55 & 3,27 & 5 & 1,6 & 3,75 & 1,99 & 2,44 \\
\hline $\mathrm{Eu} / \mathrm{P}$ & $\begin{array}{l}\text { Sebastiania commersoniana (Baill.) L. B. } \\
\text { Sm. \& Downs }\end{array}$ & & & & & 8,7 & 6,28 & 4,65 & 6,55 & & & & \\
\hline $\mathrm{Mo} / \mathrm{T}$ & $\begin{array}{l}\text { Sorocea bonplandii (Baill.) W. C. Burger, } \\
\text { Lanj. \& Wess. Boer }\end{array}$ & & & & & & & & & 1,96 & 4,1 & 2,01 & 2,69 \\
\hline $\mathrm{Me} / \mathrm{T}$ & Trichilia catigua A. Juss. & 5,06 & 4,95 & 1,78 & 3,93 & & & & & 5,15 & 8,53 & 6,19 & 6,62 \\
\hline $\mathrm{Me} / \mathrm{T}$ & Trichilia claussenii C.DC. & 16,9 & 13 & 9,33 & 13,1 & & & & & & & & \\
\hline $\mathrm{Me} / \mathrm{T}$ & Trichilia elegans A. Juss. & & & & & & & & & 3,56 & 6,14 & 3,83 & 4,51 \\
\hline \multirow[t]{4}{*}{$\mathrm{Ur} / \mathrm{I}$} & Urera baccifera (L.) Gaudich. ex Wedd. & & & & & & & & & 0,98 & 2,39 & 1,1 & 1,49 \\
\hline & Soma das 10 espécies com maior VI & 65,8 & 62 & 55,7 & 61,1 & 56,8 & 51,2 & 66,4 & 58,1 & 77,9 & 62,1 & 76,7 & 72,2 \\
\hline & Outras espécies arbóreas e "cipós" & 34,3 & 38,1 & 44,3 & 38,9 & 43,3 & 48,8 & 33,6 & 41,9 & 22,1 & 37,9 & 23,3 & 27,8 \\
\hline & & 100 & 100 & 100 & 100 & 100 & 100 & 100 & 100 & 100 & 100 & 100 & 100 \\
\hline
\end{tabular}

Em que: Fam: Família - La: Lauraceae; Sal: Salicaceae; My: Myrtaceae; Sap: Sapotaceae; Bo: Boraginaceae; Sa: Sapindaceae; Eu: Euphorbiaceae; Ma: Malvaceae; Fa: Fabaceae; Mo: Moraceae; Me: Meliaceae; Ur: Urticaceae; GE: Grupo ecológico; I: Inicial; T: Tardia; P: Plástica. DR: Densidade Relativa; DoR: Dominância Relativa; FR: Frequência Relativa; VI\%: Valor de Importância percentual. G1: $\left(\sum \mathrm{DA}=550,2 ; \sum \mathrm{FA}=418,5 ; \sum \mathrm{DoA}=27,4\right)$; G2: $\left(\sum \mathrm{DA}=505,5 ; \sum \mathrm{FA}=403,8 ; \sum \mathrm{DoA}=27,04\right)$; Sub-bosque: $\left(\sum \mathrm{DA}=1216,4 ; \sum \mathrm{FA}=437,3\right.$ e $\left.\sum \mathrm{DoA}=3,93\right)$.

predomínio devido à sua dominância, considerando que adquire expressivo crescimento em diâmetro (CARVALHO, 2006).

As espécies melhor hierarquizadas (Tabela 1) no G1 foram, predominantemente, do grupo ecológico das tardias, enquanto no G2 ocorreram espécies iniciais e tardias na mesma proporção. Tal situação corrobora o fato que mesmo o G2 sendo mais alterado encontra-se, também, em estágio sucessional intermediário. Tais espécies podem ser destacadas por proporcionar expressivo papel de sustentação na área. 
No sub-bosque $(15 \leq \mathrm{CAP}<30)$, ocorreram 37 espécies, 31 gêneros e 17 famílias, destacando-se Myrtaceae e Sapindaceae, respectivamente, com cinco e quatro espécies. A avaliação da diversidade para o índice de Shannon foi de 1,66 e a equabilidade, de 0,46 . A baixa riqueza e diversidade no sub-bosque, já foi observada por Sccoti et al. (2011). A baixa diversidade nesse estudo pode ser explicada, principalmente, pela alta densidade de Actinostemon concolor, que correspondeu a mais da metade dos indivíduos amostrados, consequentemente, reduzindo a equabilidade.

Entre as dez espécies melhor hierarquizadas no sub-bosque, a maioria apresenta característica tardia (Tabela 1), enfatizando o fato de que sob o dossel da floresta predominam as tolerantes à sombra. Dentre as com maior valor de importância (VI) cita-se: Actinostemon concolor (43,92\%), Trichilia claussenii (6,62\%), Trichilia elegans (4,51\%), Eugenia rostrifolia D.Legrand (3,30\%), Sorocea bonplandii (Baill.) W. C. Burger, Lanj. \& Wess. Boer (2,69\%), também com grande destaque à forma de vida cipó $(14,54 \%$ de representatividade na área). Todos os parâmetros contribuíram para o destaque de Actinostemon concolor no subbosque da floresta que, além de representar $57,30 \%$ dos indivíduos, também esteve presente em, aproximadamente, $94 \%$ das unidades amostradas.

A espécie Actinostemon concolor está classificada no grupo ecológico das pioneiras (RIO GRANDE DO SUL, 2007) e esciófila (CRESTANA et al., 2006). Entretanto, na região de estudo, essa espécie é comumente encontrada no sub-bosque das florestas e ausente em ambientes com maior intensidade luminosa, como nas bordas e clareiras, conforme descrito por Sccoti et al. (2011). Assim, o enriquecimento com esta espécie em áreas alteradas na região é promissor, quando se visa dar maior proteção ao solo no sub-bosque de floresta, em áreas com maior declividade.

As espécies Trichilia claussenii, Trichilia elegans e Sorocea bonplandii foram descritas como tipicamente tardias em Rio Grande do Sul (2007), assim como Eugenia rostrifolia por Backes e Irgang (2002). Essas, por serem comuns no subbosque, realizam também um papel importante de proteção à área.

Contudo, observa-se que a diferença entre os grupos é proporcionada, principalmente, pelas espécies predominantes, considerando a forma de ocorrência observada nos parâmetros fitossociológicos, e características silviculturais quanto à demanda de luz.

Apesar do aspecto de fragilidade ambiental da área, devido à alta suscetibilidade à erosão, as espécies arbóreo-arbustivas predominantes estão adaptadas ao ambiente, o que lhes permite cumprir importante função ambiental, como a interceptação da água da chuva, redução do escoamento superficial e estabilização de encostas.

\section{CONCLUSÕES}

O estrato arbóreo-arbustivo apresenta dois grupos definidos pelo grau de interferência antrópica no passado, e natural ao longo do tempo, dada a declividade e solos rasos.

Trichilia claussenii, Cupania vernalis e Crysophyllum marginatum são as principais espécies responsáveis pela classificação do ambiente com menor interferência antrópica.

As espécies Luehea divaricata e Sebastiania commersoniana são indicadoras de ambientes com maior intensidade de alteração.

Actinostemon concolor predomina no subbosque, podendo ser utilizada no enriquecimento de espécies ou complementar a estabilização de áreas de encosta.

O elevado número de espécies iniciais conjuntamente com as tardias, indica que, estruturalmente, a floresta encontra-se em estágio intermediário de sucessão.

Espécies como Cupania vernalis, Trichilia claussenii, Chrysophyllum marginatum, Luehea divaricata, Cordia americana, Sebastiania commersoniana, Actinostemon concolor e Trichilia elegans são espécies potenciais à estabilização de áreas com declividade acentuada e solos rasos.

\section{REFERÊNCIAS BIBLIOGRÁFICAS}

\section{ALMEIDA, C. M. de. Relação solo-fitossociologia em um remanescente de Floresta Estacional} Decidual. 2010. 74 f. Dissertação (Mestrado em Engenharia Florestal)-Universidade Federal de Santa Maria, Santa Maria, 2010.

ARAUJO, M. M.; et al. Análise de Agrupamento da Vegetação de um Fragmento de Floresta Estacional Decidual Aluvial, Cachoeira do Sul, RS, Brasil. Ciência Florestal, Santa Maria, v. 14, n. 1, p. 133-147, 2004.

BACKES, P.; IRGANG, B. Árvores do sul: guia de identificação e reconhecimento ecológico. Santa 
Cruz do Sul: Instituto Souza Cruz, 2002. 325 p. BROWER, J. E.; ZAR, J. H. Field and laboratory methods for general ecology. 2nd ed. Iowa: Brown Publishers, 1984. 226 p.

CARVALHO, P. E. R. Espécies Arbóreas Brasileiras. Brasília, DF: Embrapa Informação Tecnológica; Colombo, PR: Embrapa Florestas, v. 2, 2006. $627 \mathrm{p}$.

CRESTANA, M. de S. M. et al. Florestas - Sistema de Recuperação com Essências Nativas, Produção de Mudas e Legislações. 2. ed. Campinas: CATI, 2006. 248 p.

DENSLOW, J. S. Tropical rainforest gaps and tree species diversity. Annual Review of Ecology evolution and Systematics, Polo Alto, v. 18. p. 431-451. 1987.

FARIAS, J. A. et al. Estrutura fitossociológica de uma Floresta Estacional Decidual na região de Santa Maria, RS. Ciência Florestal, Santa Maria, n. 4, v. 1. p. 109-128, 1994.

FELFILI, J. M.; REZENDE, R. P. Conceitos e métodos em fitossociologia. Brasília: Universidade de Brasília, 2003. 68 p. (Comunicações Técnicas Florestais, 5)

FELFILI, J. M. et al. Análise multivariada em estudos de vegetação. Brasília: Universidade de Brasília, Departamento de Engenharia Florestal, 2007, 60 p.

HILL, M. O.; BUNCE, R. G. H.; SHAW, M. V. Indicator species analysis, a divisive polythetic metrod of classification, and its application, to a survey of native penewoods in Scotland. The Journal of Ecology, Oxford, v. 63, n. 2, p. 597-613, 1975.

HILL, M. O. TWINSPAN: a FORTRAN program for arranging multivariate data in na ordered two way table by classification of individual and attributes. Ithaca: Cornell University, 1979. 60 p.

LONGHI, S. J.; et al. Composição florística e estrutura da comunidade arbórea de um fragmento florestal no município de Santa Maria-Brasil. Ciência Florestal, Santa Maria, v. 9, n. 1, p. 115-133, 1999.

LORENZI, H. Árvores Brasileiras: Manual de identificação e Cultivo de Plantas Arbóreas Nativas do Brasil. Nova Odessa SP: Instituto Plantarum, 2002a. 381 p. v.1.

LORENZI, H. Árvores Brasileiras: Manual de identificação e Cultivo de Plantas Arbóreas Nativas do Brasil. Nova Odessa SP: Instituto Plantarum, 2002b. 381 p. v. 2.

McCUNE, B.; MEFFORD, M. J. PC-ORD: multivariate analysis of ecological data. Version 5. Gleneden Beach: MjM Software, 2006.

MORO, M. F.; MARTINS, F. R. Métodos de levantamento do componente arbóreo-arbustivo. In: FELFILI, J. M. et al. Fitossociologia no Brasil: Métodos e estudos de casos. Viçosa: Ed. UFV. 2011. 174-211.

MUELLER-DOMBOIS, D.; ELLENBERGER, H. Aims and Methods of vegetation Ecology. New York: Jonh Wiley \& Sons, 1974. 547 p.

ODUM, E. Fundamentos de ecologia. 5. ed. Lisboa: Fundação Calouste Gulbenkian, 1997. 927 p.

RIBEIRO, S. B.; et al. Diversidade e Classificação da Comunidade Arbórea da Floresta Ombrófila Mista da Flona de São Francisco de Paula, RS. Ciência Florestal, Santa Maria, v. 17, n. 2, p. 101-108, 2007. 85-103.

RIO GRANDE DO SUL. Secretaria Estadual do Meio Ambiente. Departamento de Florestas e Áreas Protegidas. Diretrizes ambientais para restauração de matas ciliares. Porto Alegre: SEMA, 2007. 33 p.

SCIPIONI, M. C. et al. Regeneração Natural de um Fragmento da Floresta Estacional na Reserva Biológica do Ibicuí-Mirim (RS). Revista Floresta, Curitiba, v. 39, n. 3, p. 675-690, 2009.

SCIPIONI, M. C. et al. Análise dos padrões florísticos e estruturais de uma comunidade arbóreaarbustiva em um gradiente de solo e relevo. In: SCHUMACHER, M. V. et al. (Orgs.). A Floresta Estacional Subtropical: caracterização e ecologia no rebordo do Planalto Meridional. Santa Maria: Pallotti, 2011.

SCCOTI, M. S. V. et al. Mecanismos de Regeneração Natural em Remanescente de Floresta Estacional Decidual. Ciência Florestal, Santa Maria, v. 21, n. 3, p. 459-472, 2011. 